\section{O estresse na atividade gerencial do enfermeiro ${ }^{1}$}

\author{
Liana Lautert, ${ }^{2}$ Enaura H. B. Chaves ${ }^{2}$ \\ e Gisela M. S. S. de Moura²
}

\section{RESUMO}

O trabalho do enfermeiro, principalmente no âmbito hospitalar, está, conforme diversos estudos, entre os que mais geram estresse em seus profissionais. Dessa forma, o objetivo desta investigação foi identificar as fontes geradoras de estresse na atividade gerencial do enfermeiro que trabalha no hospital e as principais alterações que o estresse pode acarretar sobre a saúde desse profissional. Trata-se de uma pesquisa quantitativa com uma amostra de 207 enfermeiros, realizada em 1996 em um hospital universitário na cidade de Porto Alegre, RS, Brasil. Utilizou-se um questionário auto-aplicável com questões relativas às fontes de estresse e à presença de sintomas de estresse. O questionário incluiu, também, questões sobre os sentimentos dos enfermeiros em relação a determinadas condições de trabalho e levantou dados demográficos e hábitos de vida da amostra. Os participantes do estudo tinham idade média de 35,8 anos e trabalhavam, em média, há 8,5 anos nos diferentes setores do hospital. Dos respondentes, $48 \%$ estavam estressados. A sobrecarga de trabalho foi a fonte que determinou a maior estimativa de risco relativo de estresse $(6,1)$. Em relação aos sintomas de estresse, as alterações cardiovasculares foram as que tiveram maior incidência nos auto-relatos. No entanto, as alterações gastrintestinais estiveram relacionadas com um risco maior para estresse $(5,3)$. O gerenciamento de pessoal foi a fonte de estresse que apresentou maior número de correlações significativas com os sintomas de estresse. Por outro lado, as alterações imunitarias foram as que mais se correlacionaram com as fontes de estresse. Os resultados sugerem que o estresse gerado pela atividade gerencial do enfermeiro desencadeia alterações na saúde.

Pesquisa apresentada no VI Colóquio Pan-Americano de Investigação em Enfermagem, realizado na cidade de Ribeirão Preto, SP, Brasil, em maio de 1998.

2 Universidade Federal do Rio Grande do Sul (UFRGS), Escola de Enfermagem, Porto Alegre, RS, Brasil. Correspondência e pedidos de separatas devem ser enviados a Liana Lautert no seguinte endereço: Rua São Manoel 963, CEP 90620-110, Porto Alegre, RS, Brasil. E-mail: lila@enf.ufrgs.br
Durante décadas, o tema do estresse tem sido estudado sob diversos enfoques. As investigações têm demonstrado que os eventos estressantes podem vir a ser fatores etiológicos de vários problemas físicos e emocionais. Nessas investigações, o estresse tem sido conceituado, sucessivamente, como estímulo, resposta e interação.

O conceito de estímulo foi desenvolvido a partir do princípio de forças externas que produzem alterações transitórias ou permanentes sobre os indivíduos. Essas forças referem-se a eventos denominados estressores, que podem ser considerados, de modo objetivo e universal, como ameaçadores para o indivíduo (1). Posteriormente, o estresse passou a ser considerado uma resposta (fisiológica, cognitiva ou motora) do indivíduo ante um determinado estímulo (estressor).

Nas investigações realizadas a partir da década de 80, o estresse passou a ser conceituado sob a perspectiva da interação psicológica e idiossincrática (2), onde um evento é estressante na medida em que o indivíduo o percebe e valora como tal. Isto supõe a consideração do estresse como um processo interacional entre o acontecimento objetivo, sua percepção pelo sujeito e o conseqüente afrontamento.

A partir desses pressupostos, o estresse é definido como um conceito relacional mediado cognitivamente e que reflete a relação entre a pessoa e o ambiente apreciado por ela como difícil ou que excede seus recursos, colocando em risco o seu bemestar. Podemos acrescentar, ainda, que o estresse só ocorre quando as demandas representam um desejo que o indivíduo é incapaz de alcançar (3).

É inegável que o trabalho, tal como é entendido na atualidade, exerce notável influência sobre o comportamento humano. Conforme alguns autores, seria lógico pensar que o organismo de um indivíduo que enfrenta exigências incoerentes, ou pressões no sentido de adotar condutas que não estão de acordo com seus objetivos e expectativas, não terá êxito (4). Logo, o conceito de estresse ocupacional também pode ser encarado sob a perspectiva transacional, onde existe uma interação entre o indivíduo e a situação estressante. Ou seja, o estresse ocupacional está determinado pela percepção que o trabalhador tem das demandas existentes no ambiente de trabalho e por sua habilidade para enfrentá-las (5). 


\section{Estressores ocupacionais}

Diferentes investigadores têm enumerado e classificado os estressores, organizando-os em categorias que permitam análises sistemáticas. Para esta investigação, agrupamos os potenciais estressores ocupacionais em dois grupos: os relacionados ao ambiente e os relacionados às demandas do trabalho.

As primeiras investigações sobre o estresse ocupacional foram realizadas com trabalhadores de fábricas, enfocando aspectos do ambiente físico de trabalho. Os estressores identificados apontavam, principalmente, para as conseqüências psicológicas e ergonômicas sobre a saúde do trabalhador (6-9).

Em relação às demandas do trabalho, estas referem-se à execução do trabalho em si. Entre os estressores presentes no desempenho da atividade estão o trabalho por turnos e o trabalho noturno, visto que um percentual significativo de pessoas que trabalham nesse sistema de horário relata uma série de transtornos, principalmente físicos $(3,10,11)$.

A sobrecarga de trabalho, tanto em termos quantitativos como qualitativos, é outra fonte freqüentemente associada ao estresse $(8,12-16)$. O excesso de horas trabalhadas reduz as oportunidades de apoio social do indivíduo, causando insatisfação, tensão e outros problemas de saúde. Por outro lado, a falta de trabalho pode causar sensação de tédio ao indivíduo (3).

Outra característica responsável por diferentes graus de estresse é a medida pela qual um ambiente de trabalho permite ao indivíduo controlar as atividades que realiza, tanto intrinsecamente, em termos da planificação e determinação de procedimentos a utilizar, como extrinsecamente, em termos de salário, benefícios e horários $(16,17)$. A falta de controle sobre o trabalho, assim como a responsabilidade excessiva, produzem conseqüências psicológicas e somáticas negativas $(3,18)$. Por outro lado, o indivíduo, muitas vezes, está exposto a fatores situacionais que por si só geram incertezas e ameaça, originando processos antecipatórios de afrontamento (19). A falta de controle tem sido amplamente relacionada a estresse e alterações de saúde tais como úlceras gástricas, imunossupressão e outros (20). Assim, também a duração da situação pode determinar um estresse agudo ou crônico.

A variedade das tarefas também tem relação significativa com a satisfação no trabalho. Quanto maior o número de estímulos novos, mais estressante a situação. Por outro lado, a pouca variedade das tarefas pode estar associada a ansiedade e depressão; o trabalho rotineiro e contínuo, durante anos, diminui a flexibilidade (3).

O conflito de funções, por sua vez, se refere à qualidade e à natureza da informação de que o indiví- duo dispõe para avaliar uma situação. Ele ocorre, por exemplo, quando o indivíduo se encontra entre os interesses do cliente e os da empresa. Quanto mais ambíguas as condições da situação, maior a influência das variáveis pessoais na análise e maior o risco para o desenvolvimento de estresse $(21,22)$.

A qualidade das relações interpessoais é outro fator importante na hora de determinar o potencial estressor $(4,16,17)$. A falta de coesão do grupo é uma das características que pode facilmente causar estresse. O conflito no grupo de trabalho cumpre funções positivas quando estimula a busca de soluções para o problema; no entanto, caso a situação de conflito seja contínua, poderá gerar frustrações, insatisfação e moléstias somáticas, por exemplo (3).

Também a segurança e a estabilidade na carreira afetam um percentual importante de pessoas. A carreira de um indivíduo pode gerar preocupações relacionadas a mudanças no posto de trabalho, mudanças de profissão, ou falta de promoção $(4,17)$.

No desenvolvimento da carreira existem diferentes estressores, relacionados a cada etapa. Na fase inicial pode haver discrepâncias entre as expectativas do indivíduo e a realidade. $\mathrm{Na}$ fase de consolidação pode ocorrer um desequilíbrio entre a carreira, as demandas do trabalho e as demandas familiares; e na etapa de manutenção há estresse quando existe um descompasso entre o êxito na carreira e o fracasso pessoal (3).

\section{Características pessoais implicadas no estresse}

Uma das características individuais que interfere na percepção do ambiente é o grau de ansiedade do indivíduo. A ansiedade pode causar bloqueios de memória e os indivíduos mais ansiosos tendem a render menos em tarefas onde são avaliadas a retenção de materiais previamente aprendidos (22). Outra característica freqüentemente relacionada ao estresse é o padrão de conduta conhecido como tipo A. Alguns estudos têm demonstrado que pessoas com padrão de conduta tipo A trabalham mais horas e dias ao ano e estão mais identificadas com a organização do trabalho. Por outro lado, têm especial dificuldade para delegar funções $(22,23)$.

\section{Características gerais implicadas na resposta de estresse}

O avanço das técnicas de determinação bioquímica e hemodinâmica tem auxiliado nas investigações sobre as repercussões fisiológicas dos estressores sobre o organismo de animais e humanos. Os níveis de colesterol, catecolaminas e hormônios, 
entre outros, têm sido analisados e correlacionados com eventos estressantes. No entanto, os resultados dessas investigações apresentam grande variabilidade, de forma que, ao investigar este tipo de correlação, é necessário que se estabeleça uma linha de base e que se utilizem medidas de repetição (20).

A resposta hormonal do organismo aos agentes estressores é complexa e engloba praticamente todos os hormônios e neuropeptídeos (24). A mobilização do organismo e a conseqüente ativação fisiológica frente a uma situação definida como ameaçadora inicia-se via hipotálamo, onde é ativado um dos três eixos de resposta ao estresse (3).

O eixo I, ou neural, parece ser disparado de forma imediata sempre que o indivíduo percebe uma situação de alerta, ativando o sistema nervoso simpático (aumento da respiração, do ritmo cardíaco, da liberação da glicose e outros) e o sistema nervoso periférico (regulação do nível de tensão muscular). O eixo II, ou neuroendócrino, é ativado quando as situações de estresse são mantidas por mais tempo. As fibras simpáticas, responsáveis pela enervação da medula adrenal, estimulam o eixo II, originando a liberação de epinefrina e noradrenalina. O disparo do eixo III, ou endócrino, é mais lento que os anteriores e seus efeitos mais duradouros, requerendo uma situação de estresse mais prolongada e intensa. O eixo III parece ser disparado seletivamente quando a pessoa não dispõe de estratégias para enfrentar a situação de estresse (3).

Em geral, as condições de estresse afetam os processos de avaliação, devido às distorções cognitivas, afetivas e perceptivas que o indivíduo pode sofrer. Por isso, é importante discutir a forma como o indivíduo avalia a situação de estresse.

A avaliação primária consiste em analisar se o evento é positivo ou não e em avaliar suas conseqüências. A avaliação secundária tem, como objeto de análise, a capacidade de afrontamento do indivíduo frente ao que acaba de avaliar. Ambas avaliações estão interrelacionadas. Antecedendo estas avaliações, podemos considerar a existência de uma avaliação automática prévia, de caráter emocional e inconsciente, que determina a avaliação posterior (3). O terceiro momento da avaliação da situação de estresse reside nas estratégias de afrontamento que o indivíduo usará. Elas podem ser classificadas em duas categorias, quanto à resolução do problema: modificar o problema que gera estresse ou modificar a resposta emocional (19).

Em relação especificamente ao trabalho do enfermeiro, verificamos que um grande percentual de estudos psicológicos e sociológicos $(4,11,14-16)$ têm demonstrado que essa profissão, principalmente no âmbito hospitalar, é uma das que mais estresse origina, apesar de tratar-se de uma atividade socialmente útil. Dessa forma, o objetivo do presente tra- balho foi investigar quais as principais fontes geradoras de estresse na atividade gerencial do enfermeiro que trabalha no hospital, assim como as alterações que essas fontes de estresse podem acarretar à saúde desse profissional.

\section{MATERIAIS E MÉTODOS}

O presente trabalho trata de uma pesquisa quantitativa exploratória e descritiva, do tipo pesquisa de opinião (survey). Este tipo de pesquisa permite a obtenção de informações através de auto-relatos. Os dados assim coletados podem se referir a ações, conhecimentos, opiniões, atitudes e valores dos participantes (25). O levantamento de dados ocorreu no período de agosto a novembro de 1996.

A população da pesquisa foi constituída pelos enfermeiros que trabalhavam em um hospital universitário de grande porte na cidade de Porto Alegre, Estado do Rio Grande do Sul, Brasil. A amostra foi casual simples, composta por 207 enfermeiros que se dispuseram a participar do estudo através do consentimento livre e informado, perfazendo $67 \%$ da população.

Utilizamos um questionário auto-aplicável (anexo 1). Em sua primeira parte encontram-se as questões relativas às fontes de estresse na atividade gerencial dos enfermeiros (bloco I). A segunda parte trata dos sintomas de estresse (bloco II). As afirmativas desses dois blocos foram apresentadas sob forma de escala de Likert, que permite discriminar entre pontos de vista diferentes. O bloco III apresenta questões que investigam os sentimentos dos enfermeiros em relação a algumas condições de trabalho. Na parte final foram coletados os dados demográficos e alguns hábitos de vida da amostra.

Um teste piloto foi realizado para validar o enunciado das questões do bloco I do questionário, adaptadas para enfermeiros que trabalham em hospital, uma vez que este teste foi elaborado originalmente para identificar o estresse na atividade gerencial de indivíduos que atuam em empresas comerciais. A versão original do questionário (26) foi aplicada a um grupo de 12 enfermeiros e, posteriormente, reformulada. A versão final foi testada com outro grupo de sete enfermeiros.

Em uma primeira etapa, as questões referentes às fontes de estresse tiveram seu conteúdo analisado pelas autoras e foram agrupadas, de acordo com sua semelhança semântica, em cinco categorias: conflito de funções (itens $2,4,18$, 33, 39-41 e 49 do bloco I) (anexo 1), sobrecarga de trabalho (itens 3,8 , $12-15,17,19$ e 22), relacionamento interpessoal (itens 11, 21, 25, 34-38, 42 e 43), gerenciamento de pessoal (itens 10, 26-30, 46 e 48) e situações críticas 
(itens $1,5-7,9,16,20,23,24,31,32,44,45$ e 47). Este procedimento prendeu-se ao fato de que itens individuais são menos fidedignos do que os testes inteiros (27). Os questionários foram distribuídos juntamente com o termo de consentimento e com envelopes de retorno, assegurando o sigilo dos dados. Os dados coletados foram digitados em uma planilha do programa estatístico Epi Info versão 6. Este mesmo programa foi utilizado para os cálculos preliminares do estudo. Para os demais cálculos, utilizou-se o programa Statistical Package for the Social Sciences para Windows.

Para classificar os enfermeiros como estressados ou não, optamos pelo uso da mediana. Desse modo, foi obtido um número representativo, que caracterizou o centro da distribuição dos dados sem ser afetado pelos valores extremos que não estivessem contrabalançados na direção oposta.

Para análise dos resultados das fontes de estresse na atividade gerencial dos enfermeiros (bloco I), calculamos, inicialmente, a mediana de todo o bloco e, a seguir, de cada fonte. Essa metodologia permitiu a realização de um corte para definir os enfermeiros que referem estresse em relação ao grupo e em cada fonte, bem como a identificação das fontes que causam maior estresse à amostra. Os dados foram distribuídos em tabelas de contingência 232 . A estimativa de risco relativo de estresse foi calculada em cada uma das fontes. Para análise dos resultados dos sintomas de estresse (bloco II) usamos o mesmo método. Em um segundo momento, calculamos as correlações entre as fontes e sintomas de estresse. Para tanto, utilizamos os testes de Pearson e de MantelHaenzel. Foram considerados os resultados com significância de $P=0,001$ e limite de confiança de 95\%. Para conhecer a influência dos dados demográficos sobre a produção de sintomas ou estresse na atividade gerencial do enfermeiro, usamos o teste de Levine.

\section{RESULTADOS}

Dos 207 respondentes, três não informaram a idade. Para os 204 restantes, a média de idade foi de 35,8 anos (desvio padrão $=5,666$; teste $t$ de Student $=87,242 ; P=0,000$ ). A maior concentração de indivíduos esteve na faixa de 31 a 40 anos, havendo uma queda brusca após.

A amostra foi composta por uma grande maioria de mulheres (97\%). Quanto ao estado civil, 55\% eram casados, $7 \%$ divorciados, $37 \%$ solteiros e $1 \%$ viúvos, sendo que $42 \%$ não possuíam filhos.

Cento e cinco enfermeiros (51\%) possuíam cursos de especialização. No entanto, ter ou não freqüentado algum curso de pós-graduação não se correlacionou com as fontes ou sintomas de estresse.
Os enfermeiros trabalhavam no hospital, em média, há 8,5 anos (desvio padrão $=6,318$; teste $\mathrm{t}$ de Student $=19,485 ; P=0,000$ ). A média de tempo trabalhando no mesmo setor foi de 5,6 anos (desvio padrão $=5,178$; teste $t$ de Student $=15,557 ; P=0,000$ ). A distribuição dos enfermeiros em relação a postos de trabalho e turnos foi a seguinte: $93 \%$ eram enfermeiros de unidade; $7 \%$ eram chefes de unidade; $25 \%$ trabalhavam no turno da manhã; $30 \%$ trabalhavam no turno da tarde; $36 \%$ trabalhavam no turno da noite; e $9 \%$ variavam de turno. A variável turno de trabalho não obteve correlação significativa com as demais variáveis estudadas. Também não houve correlação entre o cargo que os enfermeiros ocupavam chefia ou não - e as fontes ou sintomas de estresse.

Quanto ao uso de tabaco, verificamos que $78 \%$ não fumavam e $14 \%$ fumavam de um a 10 cigarros por dia. $O$ fato de fumar também não teve correlação com os sintomas ou fontes de estresse.

Quanto às bebidas alcoólicas, 22\% não as ingeriam jamais e $74 \%$ bebiam esporadicamente. A ingestão esporádica não teve correlação com os sintomas de estresse. No entanto, quem ingeria álcool teve um risco 1,5 vezes maior de estressar-se do que quem não bebia. Dos 160 enfermeiros que bebiam, 99 (62\%) estavam estressados na atividade de gerenciamento de pessoal (a fonte que mais se correlacionou com alterações de saúde). Quatro por cento dos enfermeiros da amostra usavam soníferos e 5\%, tranqüilizantes, apesar de $43 \%$ terem relatado alterações de sono e repouso e pertencerem ao grupo dos sintomáticos.

\section{Fontes de estresse na atividade gerencial dos enfermeiros}

A mediana do conjunto das fontes de estresse foi de 110,000 , sendo que $48 \%$ dos enfermeiros alcançaram médias superiores à mediana, constituindo o grupo de enfermeiros que referiram estresse na atividade gerencial. $\mathrm{O}$ grupo de enfermeiros com pouco estresse foi composto por $52 \%$ dos indivíduos.

A sobrecarga de trabalho foi a fonte que determinou a maior estimativa de risco relativo $(5,9)$ de estresse. A seguir estão as situações críticas, com risco de 5,09; conflito de funções, com 5,04; relacionamento interpessoal, 3,83; e gerenciamento de pessoal, 3,66. As situações críticas foram a fonte que obteve as maiores pontuações nos auto-relatos dos enfermeiros.

\section{Sintomas de estresse dos enfermeiros}

A mediana do bloco de sintomas de estresse foi de 21,000 , sendo que $51 \%$ dos enfermeiros alcançaram médias superiores à mediana, constituindo o 
grupo de enfermeiros que relataram sintomas de estresse.

As alterações cardiovasculares foram o sintoma de maior incidência nos auto-relatos dos enfermeiros, com uma mediana de 5,000. No entanto, os indivíduos com esse tipo de sintoma tinham um risco estimado em 3,7 de serem sintomáticos no conjunto dos sintomas de estresse; este risco foi menor do que o risco estimado para as alterações gastrintestinais e as alterações do sono e repouso.

Cinqüienta e dois por cento dos enfermeiros relataram alterações gastrintestinais e, destes, $41 \%$ apresentaram 5,3 vezes mais risco de serem estressados. As alterações do sono e repouso constituíram o grupo de sintomas com segundo maior risco de causar alterações na saúde. Cinqüenta e sete por cento dos enfermeiros referiram alterações do sono e repouso, sendo que, destes, $43 \%$ tiveram risco relativo de 4,1 de serem sintomáticos. Neste contingente estão incluídos 44 (21\%) enfermeiros que trabalhavam no turno noturno. No entanto, somente $4 \%$ deles faziam uso de soníferos e $5 \%$ usavam tranqüilizantes. As alterações músculo-articulares representaram um risco de 2,75; as alterações de ciclo menstrual representaram um risco de 2,57; e as alterações imunitárias representaram um risco de 2,24.

Encontramos correlação significativa entre o tempo que o enfermeiro trabalhava no setor e os sintomas cardiovasculares. Aqueles que trabalhavam em média 6 anos no setor referiam alterações cardiovasculares ( $P=0,0017$, teste de Levine). No entanto, não houve correlação entre o tempo de trabalho no hospital e o relato de sintomas.

Também houve correlação significativa entre a idade dos enfermeiros e os sintomas músculo-articulares. Os enfermeiros que referiram alterações músculo-articulares eram mais jovens do que os assintomáticos ( $P=0,002$, teste de Levine; $\mathrm{F}=9,412)$. Não houve outras correlações significativas.

\section{Correlações entre as fontes e os sintomas de estresse}

Para verificar as correlações entre as fontes de estresse da atividade gerencial com os sintomas referidos pelos enfermeiros, usamos o teste do qui quadrado $\left(x^{2}\right)$. Na presente pesquisa consideramos os achados com $95 \%$ de confiança (Pearson).

O gerenciamento de pessoal foi a fonte que apresentou maior número de correlações significativas com os sintomas de estresse (tabela 1). Os enfermeiros que se estressavam gerenciando pessoal tiveram risco de apresentar alterações imunitáricas, músculo-articulares, cardiovasculares e gastrintestinais. Por outro lado, as alterações imunitárias foram as que mais se correlacionaram com as fontes de estresse.

Dentre os participantes, 55\% expressaram a intenção de mudar de profissão; $12 \%$ relataram que tinham de fazer um esforço para ir ao trabalho; e $68 \%$ se disseram insatisfeitos com a profissão.

\section{DISCUSSÃO}

Os dados deste estudo evidenciam a pouca rotatividade dos enfermeiros neste hospital e setores, levando a inferir que se trata de uma instituição que oferece condições de trabalho que estimulam os profissionais a permanecerem mais tempo. No entanto, a considerável redução do número de enfermeiros com idade superior a 40 anos indica que uma grande maioria que atinge essa idade sai do hospital. Este fenômeno pode ser associado à inquietação que o indivíduo que se encontra nesta faixa etária sente, principalmente quando está no emprego entre 5 e 7 anos. Tal inquietação pode levá-lo a trocar de emprego e, em alguns casos, até de profissão (10). Por outro lado, enquanto atuam no hospital, os enfer-

TABELA 1. Risco estimado para sintomas decorrentes de algumas fontes estresse na atividade gerencial do enfermeiro, Porto Alegre (RS), Brasil, 1996 a

\begin{tabular}{lcccc}
\hline & \multicolumn{3}{c}{ Sintomas } & \\
\cline { 2 - 3 } \multicolumn{1}{c}{ Fontes de estresse } & $\begin{array}{c}\text { Alterações } \\
\text { imunitárias }\end{array}$ & $\begin{array}{c}\text { Alterações } \\
\text { músculo-articulares }\end{array}$ & $\begin{array}{c}\text { Alterações } \\
\text { cardiovasculares }\end{array}$ & $\begin{array}{c}\text { Alterações } \\
\text { gastrintestinais }\end{array}$ \\
\hline Gerenciamento de pessoal & $\begin{array}{c}1,63 \\
(P=0,00)\end{array}$ & $\begin{array}{c}1,63 \\
(P=0,00)\end{array}$ & $\begin{array}{c}1,33 \\
(P=0,02)\end{array}$ & $\begin{array}{c}1,28 \\
1,40\end{array}$ \\
Situações críticas & $(P=0,05)$ & $(P=0,01)$ & $(P=0,04)$ \\
Conflito de funções & 1,55 & 1,32 & - \\
Relacionamento & $(P=0,01)$ & $(P=0,03)$ & - & - \\
interpessoal & 1,38 & - & - & - \\
\hline
\end{tabular}

a Somente as correlações estatisticamente significativas são apresentadas. 
meiros demonstram preocupação com o aprimoramento profissional, fato evidenciado pelo alto índice de sujeitos com algum tipo de especialização. Este dado é relevante se pensarmos que os cursos realizados pelos enfermeiros reverterão sobre a qualidade do seu trabalho. Entre os sujeitos que informaram a área do curso, a especialização em administração se destaca, refletindo, talvez, o momento por que passam as instituições hospitalares brasileiras, exigindo eficiência no processo de trabalho e implantação de programas de qualidade.

Apesar das exigências das instituições, neste estudo não houve correlação entre ocupar cargo de chefia e fontes ou sintomas de estresse. Este fato nos causou surpresa, uma vez que supúnhamos que o cargo de chefia pudesse ter correlação significativa com as fontes de estresse (28). Cabe esclarecer que o ocupante do cargo de chefia, na maioria dos setores estudados, desenvolvia atividades assistenciais além das atividades inerentes à chefia da unidade. Estes achados nos conduziram a alguns questionamentos.

É possível que os enfermeiros chefes de unidade estivessem dividindo com os colegas do setor as atividades inerentes à chefia, de tal forma que não se sentiam sobrecarregados; ou, talvez, não estivessem tão bem preparados para a função, de forma que as atividades adicionais da chefia não representavam fontes de estresse. Ainda, é possível que o posto de chefia fosse avaliado como atraente e desafiador, mobilizando o indivíduo de tal forma que o estresse relacionado ao posto era interpretado como positivo. Por fim, é possível ainda que o número de enfermeiros chefes tenha sido muito pequeno, de forma que não foi possível estabelecer correlações significativas. Dada a peculiaridade destes resultados, pensamos que este seria um ponto a ser investigado em maior profundidade em um estudo posterior.

Quanto às fontes de estresse na atividade gerencial dos enfermeiros, a sobrecarga de trabalho é a que determina maior estimativa de risco relativo de estresse aos sujeitos do estudo. Essa fonte com freqüência é correlacionada ao estresse (16). Ela talvez não gere um sentimento tão agudo quanto as situações críticas; no entanto, é o seu contínuo que vai determinando o estresse do enfermeiro. A sobrecarga, tanto quantitativa como qualitativa, de trabalho, produz pelo menos oito sintomas de estresse psicológico e físico: tensão, insatisfação com o trabalho, redução da auto-estima, percepção de ameaça, ansiedade, aumento dos níveis de colesterol e do tônus cardíaco (17).

As situações críticas talvez tenham recebido uma pontuação alta nos auto-relatos devido à ansiedade e à insegurança que desencadeiam, causando desconforto e ameaça ao bem estar físico. A segurança pessoal requer um sentimento mínimo de previsibi- lidade e a possibilidade de poder projetar-se em um futuro mais ou menos imediato. Quando essa possibilidade não está clara, a situação adquire uma conotação ameaçadora. Entretanto, cabe lembrar que os fatores individuais e situacionais são interdependentes e que sua importância no estresse deriva dos processos cognitivos que os suportam (19).

Já o conflito de funções (terceira fonte estimada de risco de estresse) incide diretamente sobre a tensão laboral, reduzindo a satisfação do indivíduo e incrementando a probabilidade de abandono da carreira (17). Ele também é associado ao aumento da pressão sangüínea e da freqüência cardíaca (20).

Quanto aos sintomas de estresse, os enfermeiros que relataram alterações gastrintestinais foram os que apresentaram maior risco para sintomas no conjunto deste bloco. Esses achados nos levaram a inferir que as situações de estresse a que os enfermeiros estão expostos têm duração prolongada, pois é a ativação do eixo neuroendócrino (II) que produz as alterações gastrintestinais. Esse eixo só é ativado quando as situações de estresse são mantidas por mais tempo. A liberação de adrenalina e noradrenalina aumenta o aporte de oxigênio e glicose para o cérebro e músculos, dificultando a atividade digestiva.

O disparo do eixo endócrino (III), por sua vez, desencadeia aumento da produção de sucos gástricos, susceptibilidade a processos arterioscleróticos e redução dos mecanismos imunitários. Também pode desencadear efeitos psicológicos negativos, como o sentimento de se estar indefeso e a falta de controle, que constituem as situações críticas, referidas como a fonte geradora de maior estresse para os enfermeiros.

Já as alterações cardiovasculares, que são as mais auto-relatadas pelos enfermeiros, são as primeiras manifestações decorrentes da atividade do eixo neural (I), aumentando o ritmo cardíaco e respiratório. As alterações músculo-articulares, que também são características da ativação do eixo neural, foram colocadas em quarto lugar entre os sintomas de estresse e se correlacionaram com menor idade. Assim, podemos inferir que podem estar diretamente relacionadas à tensão experimentada pelos enfermeiros, pois sabemos que, à medida em que o sujeito vai adquirindo experiência, vai se ajustando à situação de trabalho e, em conseqüência, afrontando melhor as situações quotidianas e compreendendo sua dinâmica.

As alterações músculo-articulares, além de se correlacionarem com a idade, também se relacionaram com três das cinco fontes de estresse, evidenciando que se constituem em manifestações comuns entre os sujeitos desta investigação. Podemos inferir que a ergonomia do trabalho do enfermeiro o força, muitas vezes, a realizar atividades em posturas inadequadas e forçadas, potencializando o aparecimento destas alterações. 
Cabe lembrar que os indivíduos com padrão de conduta tipo A, frente a condições estressantes, costumam informar níveis menores de alterações cardiovasculares em conseqüência da utilização de seu mecanismo de atenção, centrado na satisfação de suas metas, o que os expõe a um risco maior de problemas cardiovasculares, independentemente dos riscos tradicionalmente associados (29).

As alterações imunitárias, quando relacionadas com as demais do bloco, foram as que tiveram menor estimativa de risco entre os sintomas auto-relatados. No entanto, foram as que mais se correlacionaram com as fontes de estresse. As alterações imunitárias representam os efeitos mais crônicos do estresse e costumam ocorrer com a ativação do eixo endócrino. Os sintomas que podem surgir a partir dessas alterações são os resfriados, estados gripais, lesões herpéticas e crises asmáticas, entre outras.

Quanto às fontes de estresse na atividade gerencial, o gerenciamento de pessoal foi a fonte que mais se correlacionou com os sintomas, seguido pelas situações críticas e pelo conflito de funções. Na literatura, as situações críticas e o conflito de funções são relatados como responsáveis pelo desenvolvimento de alterações imunitárias, músculo-esqueléticas e cardiovasculares (20). Tais associações foram confirmadas nesta investigação.

A sobrecarga de trabalho, primeira fonte de estresse na atividade gerencial do enfermeiro, não obteve correlação com os sintomas. No entanto, como ela reduz as oportunidades de apoio social, acaba causando insatisfação com o trabalho $(13,16)$. Também sabemos que a sobrecarga de trabalho, que apareceu como a fonte de maior risco para estresse, é um dos fatores que gera insatisfação ao indivíduo. A esse respeito cabe destacar o expressivo número de enfermeiros que expressaram sua insatisfação e a intenção de trocar de profissão. Talvez esta pretensão esteja relacionada à percepção de sobrecarga de trabalho associada à média de tempo que trabalham no hospital (8 anos). Nesta fase, em geral, o indivíduo procura o equilíbrio entre as demandas do trabalho e as familiares. Cabe lembrar que o conflito de funções é um estressor que pode influenciar o sentimento de abandono da carreira.

Finalmente, ao comentarmos as fontes e sintomas de estresse, cabe lembrar do papel decisivo da forma de afrontamento no surgimento do estresse e, em conseqüência, de seus sintomas. O problema de um indivíduo estar estressado ou não conjuga a influência da estrutura do sistema com a forma como o indivíduo afronta as demandas do meio; portanto, o modo de vida e a atividade de uma pessoa contribuem para determinar sua saúde e enfermidade (30).

\section{CONCLUSÕES}

Embora nos pareça que os resultados do presente trabalho sejam bastante elucidativos, é importante alertar para a tendência dos indivíduos de relatarem de forma seletiva os autoinformes, bem como para a influência das variáveis pessoais dos enfermeiros, que não foram contempladas neste estudo.

$\mathrm{O}$ estresse na atividade gerencial do enfermeiro está relacionado a diferentes variáveis, tanto da situação como do próprio indivíduo. No entanto, consideramos que não é fácil delimitar o ponto onde um fator se sobrepõe ao outro. Contudo, alguns aspectos merecem ser apreciados quando fazemos referência ao estresse do enfermeiro que trabalha no hospital. Um ponto importante a destacar é que o estresse desencadeado pela atividade gerencial do enfermeiro no hospital causa alterações em sua saúde, principalmente imunológicas e músculoarticulares, cardiovasculares e gastrintestinais.

Outro aspecto importante é a estimativa de que as situações críticas causam cinco vezes mais estresse na atividade gerencial e se correlacionam com as alterações imunitárias, músculo-articulares e cardiovasculares. Consideramos que os fatores que fazem parte da fonte "situações críticas" merecem nossa atenção no sentido de prepararmos o enfermeiro para assumir a atividade gerencial, uma vez que ela é parte inerente do cotidiano desta atividade.

É bem possível que o estresse relacionado à sobrecarga de trabalho, relatado pelos enfermeiros, seja o responsável pelo sentimento de insatisfação com o trabalho, bem como pelo desejo de trocar de profissão. Estes resultados nos incitam a refletir sobre as condições nas quais o trabalho é desenvolvido nesta instituição, condições que podem estar contribuindo para o estresse desses enfermeiros.

\section{REFERENCIAS}

1. Selye H. The stress of the life. New York: McGraw-Hill; 1956.

2. Moos RH, Swindle RW. Person: environment transactions and the stressor- appraisal-coping. Psychol Inquiry 1990; 25:122-133.

3. Peiró JM. Desencadenantes del estrés laboral. Madrid: Eudema; 1993.
4. Llopis SA, Calvo IR, Carbó RS, Chirinos FSP, Vicenta CG, Garcia JR. Motivación laboral: creación de círculos de calidad. Rol de Enfermería 1993:176:32-38. 
5. Cox T. Stress, coping and problem solving. Work and Stress 1987;1(1):5-14.

6. Ardila R. Psicología del trabajo. 2a ed. Santiago: Editorial Universitária; 1986.

7. Laurell A, Noriega M. Processo de produção e saúde: trabalho e desgaste operário. São Paulo: Hucitec; 1989.

8. Paraguay AIB. Estresse, conteúdo e organização do trabalho: Contribuições da ergonomia para melhoria das condições de trabalho. Rev Bras Saude Ocupac 1990;70(18):40-43.

9. Pitta A. Hospital: dor e morte como ofício. 2a ed. São Paulo: Hucitec; 1991.

10. Cabanes CI, Pujol AR. Faltan enfermeros asistenciales. Rol de Enfermería 1992;167:27-33.

11. Escribá V. Condiciones de trabajo en el hospital. Rol de Enfermería 1992; 170: 67-71.

12. Ivancevich JM, Matteson MT. Stress and work: a managerial perspective. Palo Alto: Scott Foresman and Company; 1980.

13. Cherniss C. Staff burnout: job stress in the human services. 4a ed. Beverly Hills: Sage; 1983.

14. Dewe PJ. Stressor frequency, tension, tiredness and coping: some measurement issues and a comparison across nursing groups. J Adv Nurs 1989; 14(2):308-320

15. Bianchi ER. Estresse em enfermagem: análise da atuação do enfermeiro em centro cirúrgico [tese de doutorado]. São Paulo: Universidade de São Paulo; 1990

16. Fornés J. Respuesta emocional al estrés laboral. Rol de Enfermería 1994;186: 31-39.

17. Peiró JM. Psicología de la organizacion. Volume I e II. Madrid: Universidad Nacional de Educación a Distancia; 1992.

18. Foster V. Supervisor impact on stress and burnout. Todays OR Nurse 1987;9(12):24-29.

19. Lazarus RS, Folkman S. Estrés y procesos cognitivos. Barcelona: Martinez Roca; 1987.

20. Peiró J, Salvador A. Control del estrés laboral. Madrid: Eudema; 1993.

21. Heim E. Stressors in health occupations Do females have a greater health risk? Z Psychosom Med Psychoanal 1992;38(3): 207-226.

22. Bermúdez J. Psicología de la personalidad. 5a ed. Madrid: UNED; 1994.

23. Bermúdez J, Sánchez A. Factores psicologicos asociados al desarrollo de alteraciones cardiovasculares. Em: Sandín B, Moreno J. Procesos emocionales y salud. Madrid: UNED; 1989. p. 13-44.

24. Sandín B. Estrés, coping y alteraciones psicofisiológicas. Em: Sandín B, Moreno J. Procesos emocionales y salud. Madrid: UNED; 1989. p. 45-72.
25. Polit DF, Hungler BP. Fundamentos de pesquisa em enfermagem. 3a ed. Porto Alegre: Artes Médicas; 1995.

26. Chaves EHB. Pesquisando a existência do stress na atividade gerencial do enfermeiro: um estudo inicial [dissertação de mestrado]. Porto Alegre: Universidade Federal do Rio Grande do Sul; 1991.

27. Kerlinger FN. Metodologia da pesquisa em ciências sociais. São Paulo: EPU; 1980.

28. Lautert L. O desgaste profissional do enfermeiro [tese de doutorado]. Salamanca: Universidad Pontificia de Salamanca; 1995.

29. Sánchez-Elvira A, Bermúdez J, Pérez AM. Dirección predictiva de los componentes del patrón de conducta tipo A en la información de síntomas psicofisiológicos. Em: Ibánez E. Psicología de la salud y estilo de vida. Valencia: Promolibro; 1991. p. 175-195.

30. Labrador FJ, Crespo M. Estrés. Trastornos psicofisiológicos. Salamanca: Eudema; 1993.

Manuscrito recebido em 28 de janeiro de 1999 Aceito em versão revisada em 16 de agosto de 1999.

ANEXO 1. Instrumento de coleta de dados, pesquisa sobre o estresse na atividade gerencial do enfermeiro de hospital, Porto Alegre (RS), Brasil, 1996

\section{PESQUISA SOBRE O ESTRESSE NA ATIVIDADE GERENCIAL DO ENFERMEIRO}

Considerando como período base o último ano de sua atuação profissional, solicitamos sua valiosa contribuição para a realização de presente pesquisa. Da precisão e coerência de suas respostas depende a exatidão dos resultados.

\section{BLOCO I - FATORES E FONTES DE ESTRESSE}

Entende-se por estresse o fenômeno de não se conseguir uma adequada adaptação frente a situações percebidas como agressoras ao indivíduo/ organismo. Para medir a intensidade de estresse provocada pelas situações abaixo, circule a alternativa que corresponde à sua escolha de acordo com a escala:

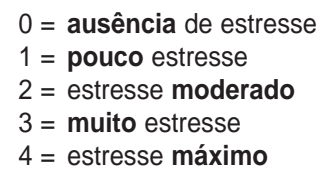

Se a situação não se aplica a seu caso, coloque um "x" na última coluna.

\begin{tabular}{|c|c|c|c|c|c|c|}
\hline ESCALA DE ESTRESSE & $\begin{array}{c}\text { Ausência de } \\
\text { estresse }\end{array}$ & $\begin{array}{l}\text { Pouco } \\
\text { estresse }\end{array}$ & $\begin{array}{l}\text { Estresse } \\
\text { moderado }\end{array}$ & $\begin{array}{l}\text { Muito } \\
\text { estresse }\end{array}$ & $\begin{array}{l}\text { Estresse } \\
\text { máximo }\end{array}$ & $\begin{array}{l}\text { NÃO SE } \\
\text { APLICA }\end{array}$ \\
\hline 1. Reuniões com a chefia & 0 & 1 & 2 & 3 & 4 & \\
\hline 3. Implantar decisões importantes & 0 & 1 & 2 & 3 & 4 & \\
\hline 4. Intermediar os conflitos entre áreas, setores, unidades & 0 & 1 & 2 & 3 & 4 & \\
\hline 5. Enfrentar as críticas da chefia & 0 & 1 & 2 & 3 & 4 & \\
\hline
\end{tabular}

${ }^{1} \mathrm{O}$ presente instrumento é reaplicado no Brasil com autorização do pesquisador professor Benjamin Stora do Centre HEC-ISA, França, para fins de estudo comparativo. 


\begin{tabular}{|c|c|c|c|c|c|c|}
\hline ESCALA DE ESTRESSE & $\begin{array}{l}\text { Ausência de } \\
\text { estresse }\end{array}$ & $\begin{array}{l}\text { Pouco } \\
\text { estresse }\end{array}$ & $\begin{array}{l}\text { Estresse } \\
\text { moderado }\end{array}$ & $\begin{array}{l}\text { Muito } \\
\text { estresse }\end{array}$ & $\begin{array}{l}\text { Estresse } \\
\text { máximo }\end{array}$ & $\begin{array}{l}\text { NÃO SE } \\
\text { APLICA }\end{array}$ \\
\hline 6. Enfrentar as críticas dos subordinados & 0 & 1 & 2 & 3 & 4 & \\
\hline 7. Enfrentar as crises & 0 & 1 & 2 & 3 & 4 & \\
\hline 8. Vencer a resistência às mudanças & 0 & 1 & 2 & 3 & 4 & \\
\hline 9. Sentir-se só face à tomada de decisões importantes & 0 & 1 & 2 & 3 & 4 & \\
\hline 10. Impor decisões aos outros & 0 & 1 & 2 & 3 & 4 & \\
\hline 11. Consultar muitas pessoas antes de tomar uma decisão & 0 & 1 & 2 & 3 & 4 & \\
\hline 12. Sobrecarga da trabalho & 0 & 1 & 2 & 3 & 4 & \\
\hline 13. Pouco trabalho: atividades reduzidas & 0 & 1 & 2 & 3 & 4 & \\
\hline 14. Longas jornadas de trabalho & 0 & 1 & 2 & 3 & 4 & \\
\hline 15. Levar trabalho para casa & 0 & 1 & 2 & 3 & 4 & \\
\hline 16. Falta de poder e influência & 0 & 1 & 2 & 3 & 4 & \\
\hline 17. Assistir a grande número de reuniões de trabalho & 0 & 1 & 2 & 3 & 4 & \\
\hline 18. A organização (hospital) impõe valores, idéias e métodos que & & & & & & \\
\hline entram em conflito com os seus & 0 & 1 & 2 & 3 & 4 & \\
\hline $\begin{array}{l}\text { 19. Medo de ser ultrapassado(a) pelo ritmo de desenvolvimento } \\
\text { tecnológico da empresa }\end{array}$ & 0 & 1 & 2 & 3 & 4 & \\
\hline 20. Receio de perder seu emprego & 0 & 1 & 2 & 3 & 4 & \\
\hline 21. Disputa com colegas para assumir cargo de chefia & 0 & 1 & 2 & 3 & 4 & \\
\hline 22. Ter que realizar tarefas acima de seu nivel de competência & 0 & 1 & 2 & 3 & 4 & \\
\hline 23. Executar tarefas inferiores a seu nível de competência & 0 & 1 & 2 & 3 & 4 & \\
\hline 24. Ter subordinados pouco competentes & 0 & 1 & 2 & 3 & 4 & \\
\hline $\begin{array}{l}\text { 25. Preocupação em manter relações profissionais satisfatórias } \\
\text { 26. Contratar pessoal }\end{array}$ & 0 & 1 & 2 & 3 & 4 & \\
\hline 27. Dispensar pessoal & 0 & 1 & 2 & 3 & 4 & \\
\hline 28. Orientar e treinar pessoal & 0 & 1 & 2 & 3 & 4 & \\
\hline 29. Justificar promoção recusada a um subordinado & 0 & 1 & 2 & 3 & 4 & \\
\hline 30. Discutir e/ou justificar um caso de demissão & 0 & 1 & 2 & 3 & 4 & \\
\hline 31. Incompatibilidade com superior hierárquico & 0 & 1 & 2 & 3 & 4 & \\
\hline 32. Incompetência de superior hierárquico & 0 & 1 & 2 & 3 & 4 & \\
\hline 33. Implantar metas irrealistas & 0 & 1 & 2 & 3 & 4 & \\
\hline 34. Negociar com seus pares na empresa & 0 & 1 & 2 & 3 & 4 & \\
\hline 35. Negociar com membros da equipe de saúde & 0 & 1 & 2 & 3 & 4 & \\
\hline 36. Negociar com pacientes e familiares & 0 & 1 & 2 & 3 & 4 & \\
\hline 37. Negociar com áreas de apoio & 0 & 1 & 2 & 3 & 4 & \\
\hline 38. Negociar com subordinados & 0 & 1 & 2 & 3 & 4 & \\
\hline 39. Atitude de seu(a) cônjuge com respeito à sua carreira profissional & 0 & 1 & 2 & 3 & 4 & \\
\hline 40. Conflitos entre as exigências da empresa e as obrigações familiares & 0 & 1 & 2 & 3 & 4 & \\
\hline 41. Conflitos entre a vida social e a vida familiar & 0 & 1 & 2 & 3 & 4 & \\
\hline 42. Relações com colegas & 0 & 1 & 2 & 3 & 4 & \\
\hline 43. Relações com subordinados & 0 & 1 & 2 & 3 & 4 & \\
\hline 44. Erros cometidos por você & 0 & 1 & 2 & 3 & 4 & \\
\hline 45. Sentir-se desvalorizado(a) & 0 & 1 & 2 & 3 & 4 & \\
\hline 46. Assumir cargo de chefia & 0 & 1 & 2 & 3 & 4 & \\
\hline 47. Nível de remuneração & 0 & 1 & 2 & 3 & 4 & \\
\hline 48. Gerenciar seus colaboradores & 0 & 1 & 2 & 3 & 4 & \\
\hline 49. Falta de deliberação e de comunicação na empresa & 0 & 1 & 2 & 3 & 4 & \\
\hline
\end{tabular}

\section{BLOCO II - SINTOMAS DE ESTRESSE}

Os itens abaixo relacionados representam sintomas de estresse. Para medir a presença e intensidade dos sintomas associados a situações de estresse, circule a alternativa que corresponde à sua percepção de acordo com a escala:

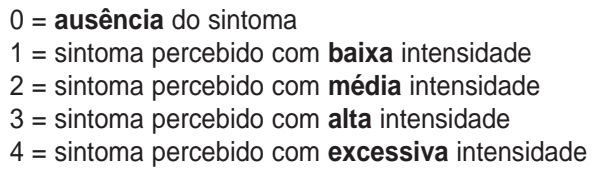




\begin{tabular}{|c|c|c|c|c|c|}
\hline ESCALA DE ESTRESSE & $\begin{array}{l}\text { ausência } \\
\text { de sintoma }\end{array}$ & $\begin{array}{c}\text { baixa } \\
\text { intensidade }\end{array}$ & $\begin{array}{c}\text { média } \\
\text { intensidade }\end{array}$ & $\begin{array}{c}\text { alta } \\
\text { intensidade }\end{array}$ & $\begin{array}{l}\text { excessiva } \\
\text { intensidade }\end{array}$ \\
\hline \multicolumn{6}{|l|}{ BLOCO 1} \\
\hline 1. Cefaléia & 0 & 1 & 2 & 3 & 4 \\
\hline 2. Palpitações & 0 & 1 & 2 & 3 & 4 \\
\hline 3. Arritmias cardíacas & 0 & 1 & 2 & 3 & 4 \\
\hline 4. Pressão arterial alta (hipertensão) & 0 & 1 & 2 & 3 & 4 \\
\hline 5. Pressão arterial baixa (hipotensão) & 0 & 1 & 2 & 3 & 4 \\
\hline 6. Sensação de dor ou pressão no peito & 0 & 1 & 2 & 3 & 4 \\
\hline 7. Torturas & 0 & 1 & 2 & 3 & 4 \\
\hline 8. Suor frio & 0 & 1 & 2 & 3 & 4 \\
\hline 9. Respiração muito rápida & 0 & 1 & 2 & 3 & 4 \\
\hline \multicolumn{6}{|l|}{ BLOCO 2} \\
\hline 10. Falta de apetite & 0 & 1 & 2 & 3 & 4 \\
\hline 11. Flatulência & 0 & 1 & 2 & 3 & 4 \\
\hline 12. Náuseas/Vômitos & 0 & 1 & 2 & 3 & 4 \\
\hline 13. Gastrites/Pirose/Úlcera/Dor no estômago & 0 & 1 & 2 & 3 & 4 \\
\hline 14. Diarréia & 0 & 1 & 2 & 3 & 4 \\
\hline 15. Constipação & 0 & 1 & 2 & 3 & 4 \\
\hline \multicolumn{6}{|l|}{ BLOCO 3} \\
\hline 16. Catarro, resfriado comum ou gripe & 0 & 1 & 2 & 3 & 4 \\
\hline 17. Hipertermia & 0 & 1 & 2 & 3 & 4 \\
\hline 18. Enfermidades infecciosas em geral & 0 & 1 & 2 & 3 & 4 \\
\hline 19. Tosse & 0 & 1 & 2 & 3 & 4 \\
\hline 20. Obstrução nasal & 0 & 1 & 2 & 3 & 4 \\
\hline 21. Sensação de falta de ar ou asma & 0 & 1 & 2 & 3 & 4 \\
\hline \multicolumn{6}{|l|}{ BLOCO 4} \\
\hline 22. Dificuldade para conciliar o sono & 0 & 1 & 2 & 3 & 4 \\
\hline 23. Insônia & 0 & 1 & 2 & 3 & 4 \\
\hline 24. Pesadelos & 0 & 1 & 2 & 3 & 4 \\
\hline 25. Necessidade excessiva de dormir & 0 & 1 & 2 & 3 & 4 \\
\hline \multicolumn{6}{|l|}{ BLOCO 5} \\
\hline 26. Rigidez e/ou dor nas articulações & 0 & 1 & 2 & 3 & 4 \\
\hline 27. Cãibras ou espasmos musculares & 0 & 1 & 2 & 3 & 4 \\
\hline 28. Dores musculares & 0 & 1 & 2 & 3 & 4 \\
\hline 29. Dores na nuca ou zona cervical & 0 & 1 & 2 & 3 & 4 \\
\hline 30. Dores na zona lombar & 0 & 1 & 2 & 3 & 4 \\
\hline \multicolumn{6}{|l|}{ BLOCO 6 (somente para mulheres) } \\
\hline 31. Hemorragias intermenstruais & 0 & 1 & 2 & 3 & 4 \\
\hline 32. Dores ou moléstias antes da menstruação & 0 & 1 & 2 & 3 & 4 \\
\hline 33. Amenorréia & 0 & 1 & 2 & 3 & 4 \\
\hline 34. Dores durante a menstruação & 0 & 1 & 2 & 3 & 4 \\
\hline 35. Ciclos irregulares & 0 & 1 & 2 & 3 & 4 \\
\hline
\end{tabular}

Considerando sue comportamento em relação ao uso de bebidas alcóolicas, fumo e medicamentos, de um modo geral, coloque um "x" no espaço correspondente à sua escolha. Seja o mais fidedigno e objetivo possível em relação à sua auto-percepção.

\section{BEBIDAS ALCÓOLICAS}

Quais são seus hábitos em matéria de bebidas?

( ) eu não bebo jamais

( ) regularmente, 1 a 2 copos por dia

( ) de tempos em tempos

( ) regularmente, 3 a 6 copos por dia

( ) 1 a 5 por dia

( ) 21 a 40 por dia

Em caso afirmativo, quantos por dia?

Em caso afirmativo, quantos por dia? 


\section{BLOCO III - TRABALHO E PROFISSÃO}

Este bloco investiga aspectos relacionados às suas condições de trabalho. Assinale com um "x" sua resposta às seguintes questões:

1. Você deve frequentemente fazer um esforço para ir trabalhar?

2. Você está satisfeito(a) com seu atual trabalho?

3. Seus dias de trabalho lhe parecem intermináveis?

4. Você pensa em mudar de posição na empresa?

5. Você tem, às vezes, vontade de mudar de profissão?

\begin{tabular}{|l|l|}
\hline $\operatorname{Sim}$ & Não \\
& \\
\hline
\end{tabular}

INFORMAÇÕES PROFISSIONAIS

Idade: $\quad$ anos $\quad$ Sexo: $\quad$ ( ) masc. $\quad$ ( ) fem.

Cargo que ocupa:

Há quanto tempo trabalha neste hospital?

Área de atuação:

Setor onde trabalha:

Há quanto tempo trabalha neste setor?

Turno de trabalho: ( ) Manhã ( ) Tarde ( ) Noite ( ) Variado

Pós-Graduação: ( ) Sim. Qual?____ Não

ABSTRACT According to several studies, nursing, especially in hospital settings, is one of the most stressful professions. The objective of this study was to identify the sources of stress related to the administrative tasks of nurses working in a hospital, as well as the main health changes that stress caused these professionals. The quantitative survey was carried out in 1996 with a sample of 207 nurses at a university hospital in the city of Porto Alegre, in the state of Rio Grande do Sul, Brazil. A questionnaire was used to collect data on stress sources and symptoms. The questionnaire also gathered demographic data, as well as information on the nurses' feelings about their working conditions. The average age of the study participants was 35.8 years, and the average time working at the hospital was 8.5 years. Among participants, $48 \%$ were considered to be stressed. Work overload was the stress source that best predicted relative risk of stress (6.1). In terms of stress symptoms, the most commonly reported ones were cardiovascular changes. However, gastrointestinal changes were related to a higher risk of stress (5.3). Managing other staff was the stress source that had the greatest number of significant correlations with stress symptoms. On the other hand, immunologic changes were the symptoms that had the highest correlation with stress sources. Our results suggest that stress related to administrative tasks in nursing may trigger changes in nurses' health. 